\title{
Comet Assay measurements: a perspective
}

\author{
T. S. Kumaravel • Barbara Vilhar • \\ Stephen P. Faux • Awadhesh N. Jha
}

Received: 16 July 2007 / Accepted: 8 October 2007 / Published online: 27 November 2007

(C) Springer Science + Business Media B.V. 2007

\begin{abstract}
The Comet Assay or single cell gel electrophoresis assay is one of the very widely used assays to microscopically detect DNA damage at the level of a single cell. The determination of damage is carried out either through visual scoring of cells (after classification into different categories on the basis of tail length and shape) or by using different commercially available or public domain software (which automatically recognise the extent of damage). In this assay, the shape, size and amount of DNA within the 'comet' play important roles in the determination of the level of damage. The use of a software in particular also provides a range of different parameters, many of which might not be relevant in determining the extent of DNA damage. As a large number of factors could influence the shape, size, identification and determination of induced damage, which includes the scoring criteria,
\end{abstract}

T. S. Kumaravel $(\bowtie) \cdot$ S. P. Faux

Toxicology Group,

Advanced Technologies (Cambridge) Ltd.,

210 Cambridge Science Park,

Cambridge CB4 0WA, UK

e-mail: ts.kumaravel@atcbiotech.com

B. Vilhar

Department of Biology, Biotechnical Faculty, University of Ljubljana,

Ljubljana, Slovenia

A. N. Jha

School of Biological Sciences, University of Plymouth, Plymouth PL4 8AA, UK staining techniques, selection of parameters (whilst using the software packages) and appearance of 'hedgehog' or 'clouds', this article aims (a) to provide an overview of evolution of measurements of DNA damage using the Comet Assay and (b) to summarise and critically analyse the advantages and disadvantages of different approaches currently being adopted whilst using this assay. It is suggested that judicious selection of different parameters, staining methods along with inter-laboratory validation and harmonisation of methodologies will further help in making this assay more robust and widely acceptable for scientific as well as regulatory studies.

Keywords Comet Assay · Single cell gel electrophoresis (SCGE) · Comet Assay measurements . Image analysis · Clouds $\cdot \%$ Tail DNA ·

Olive tail moment (OTM) - Genetic toxicology

\section{Introduction}

The Comet Assay or single cell gel electrophoresis (SCGE) assay is a rapid, sensitive and relatively simple method for detecting DNA damage at the level of individual cells (Singh et al. 1988; Comet Assay interest group website: http://cometassay.com/). It combines the simplicity of biochemical techniques for detecting DNA single strand breaks (strand breaks and incomplete excision repair sites), alkali labile sites and cross-linking, with the single cell approach typical of 
cytogenetic assays. Several reviews have been published in recent years to highlight the procedures, advantages and limitations of this assay in genotoxicological, ecotoxicological and biomonitoring studies (Collins 2004; Dixon et al. 2002; Fairbairn et al. 1995; Lee and Steinert 2003). The assay has also been successfully implemented in plant cells under laboratory conditions (Gichner et al. 2004, 2006). The main advantages of the Comet Assay include: (a) the collection of data at the level of the individual cell, allowing more robust statistical analyses, (b) the need for a small number of cells per sample $(<10,000)$, (c) sensitivity for detecting DNA damage and (d) use of any eukaryote single cell population both in vitro and in vivo, including cells obtained from exposed human populations and aquatic organisms for eco-genotoxicological studies and environmental monitoring (Collins et al. 1997a; Dixon et al. 2002; Lee and Steinert 2003; Jha 2004). The importance of this assay has also been realised in regulatory genotoxicological studies (Tice et al. 2000; Hartmann et al. 2003; Burlinson et al. 2007), and there is a move to replace some traditional assays (e.g. liver unscheduled DNA synthesis assay) in regulatory genotoxicological studies with in vivo Comet assay. In combination with certain bacterial enzymes (e.g. formamidopyrimidine glycosylase, endonuclease III, uracil-DNA glycosylases, etc.), which recognise oxidised purines and pyrimidine bases, this assay has been used to determine oxidative DNA damage that has been implicated in several health conditions (Collins et al. 1993, 1997a, b, 2001a, b; Kruman et al. 2002). This assay has also been used to show protective effects of different dietary factors in chemo-preventive studies (Bichler et al. 2007; Collins et al. 2001a, b). In combination with the fluorescence in situ hybridisation (FISH) technique (Comet-FISH), the application of this assay has also been extended to determine sequence or gene-specific damage and repair (Santos et al. 1997; McKenna et al. 2003) as well as of possible diagnostic use (Kumaravel and Bristow 2005). In addition, the assay is being used in translational research to assess whether tumour radiosensitivity (Fisher et al. 2007) and chemo-sensitivity (Smith et al. 2007) can be determined. This would allow clinicians to individualise patient management, allocating cancer therapy to those for whom it will be of most benefit and reducing the likelihood of patients receiving toxic (and as such ineffective) therapy. In view of its wide applications and uses, based on
PubMed/Web of Science, in the last 10 years, more than 4,000 papers have been published in peerreviewed scientific journals, which reflect its popularity.

The Comet Assay is based on the ability of negatively charged loops/fragments of DNA to be drawn through an agarose gel in response to an electric field. The extent of DNA migration depends directly on the DNA damage present in the cells. It should be noted that DNA lesions consisting of strand breaks after treatment with alkali either alone or in combination with certain enzymes (e.g. endonucleases) increase DNA migration, whereas DNA-DNA and DNA-protein cross-links result in retarded DNA migration compared to those in concurrent controls (Tice et al. 2000).

In this assay, a suspension of cells is mixed with low melting point agarose and spreads onto a microscope glass slide. After lysis of cells with detergent at high salt concentration, DNA unwinding and electrophoresis is carried out at a specific $\mathrm{pH}$. Unwinding of the DNA and electrophoresis at neutral $\mathrm{pH}$ (7-8) predominantly facilitates the detection of double strand breaks and cross links; unwinding and electrophoresis at $\mathrm{pH}$ 12.1-12.4 facilitates the detection of single and double strand breaks, incomplete excision repair sites and cross-links; whereas unwinding and electrophoresis at a $\mathrm{pH}$ greater than 12.6 expresses alkali labile sites in addition to all types of lesions listed above (Miyamae et al. 1997). When subjected to an electric field, the DNA migrates out of the cell, in the direction of the anode, appearing like a 'comet'. The size and shape of the comet and the distribution of DNA within the comet correlate with the extent of DNA damage (Fairbairn et al. 1995).

The determination of the shape, size and amount of DNA within comets is therefore a very important attribute of the assay if the induced damage is to be evaluated accurately. In parallel with several technical and procedural evolutions to make the assay more robust, several approaches have also evolved to quantify the extent of damage more reliably, reproducibly and meaningfully. Such quantification includes both visual examinations (i.e., photographic, occulometer or non-specific image analysis systems) or by use of commercially available or public domain specific image analysis software packages. Although visual examinations give a fairly good indication of DNA damage and can be used in situations that are considered appropriate or where specific software packages are not available, the use of specific image 

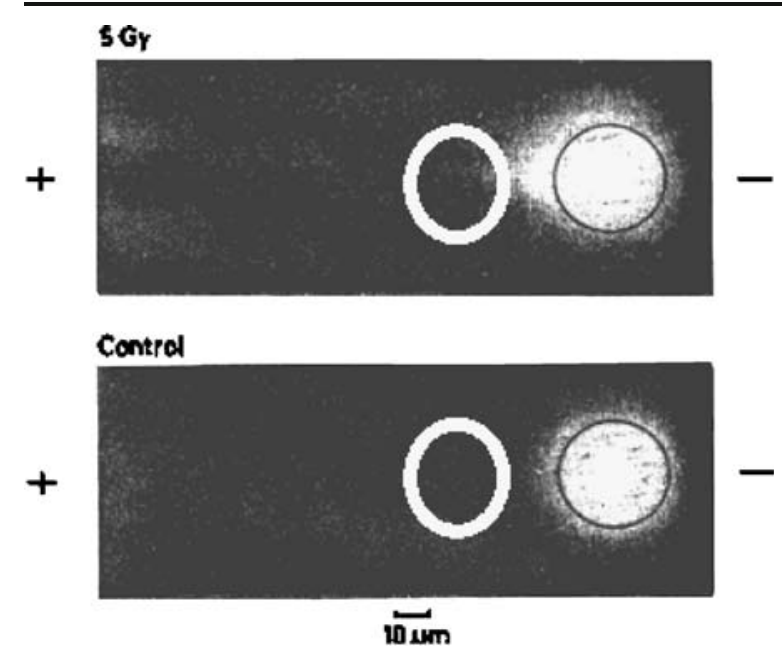

Fig. 1 Image analysis used by Ostling and Johanson (1984; modified for clarity). They measured fluorescence (using photometre) in the head and in the tail at a distance of $50 \mu \mathrm{m}$ from the centre of the head using acridine orange as the DNA binding dye

analysis software is considered to be reliable, reproducible, which provide simultaneously a range of parameters and additional information (e.g. the distribution of DNA within the comet tail, total cellular DNA content), and may also indicate different phases of cell cycle distribution, which can be useful in the interpretation of the data. Such specific software packages also facilitate easy statistical analyses, plotting and documentation of the data.

Despite being a very popular choice to determine DNA damage, there are still some concerns over the methodology used, and the type and quality of data produced using this assay. Given the importance of different measurements in determining the extent of DNA damage (and repair) in this very widely used assay, this article aims to (a) analyse the developments and our current understanding of different Comet Assay measurements (b) analyse their relative importance or use and (c) highlight future developments and perspectives.

\section{Historical perspectives and evolution of measurement procedures}

The Comet Assay was first introduced by Ostling and Johanson in 1984. This was a neutral version of the Comet Assay, and interestingly, they used quite sophisticated techniques of image analysis for quantification of the comets, using acridine orange (AO) as the DNA binding dye (Fig. 1). The fluorescence was measured with a Leitz MPV2 microscope photometer with a $\times 40$ objective using a Phloemopak filterblock $\mathrm{H} 2$ giving excitation at $390-490 \mathrm{~nm}$. The emitted light from individual cells passed an emission filter (long pass $525 \mathrm{~nm}$ ). Green fluorescence was then measured using a circular diaphragm first over the head and then over different positions on the comet tail. The

Table 1 List of various Comet Assay parameters used in published literature

\section{Parameters}

Cell area

Comet coefficient of variance

Comet distribution moment

Comet extent

Comet inertia

Comet mean

Comet mode

Comet optical intensity

Comet skew

Comet standard deviation

Head coefficient of variance

Head distribution moment

Head DNA

Head extent

Head inertia

Head mean

Head mode

Head optical intensity

Head skew

Head standard deviation

Length/height

Olive tail moment

Tail coefficient of variance

Tail distribution moment

Tail DNA

Tail extent

Tail extent moment

Tail inertia

Tail length

Tail mean

Tail mode

Tail optical intensity

Tail skew

Tail standard deviation

Tail length, Tail DNA and DNA distribution profile in the Tail are primary Comet Assay measurements (obtained by fluorescent densitometric profiles of the comets). All other measurements are derived from the three primary Comet Assay measurements (adapted from Kumaravel and Jha 2006). 
background fluorescence adjacent to the cells was subtracted. The time of illumination and between measurements were standardised to minimise fading bias. They presented their results in terms of the ratio of fluorescence $(\mathrm{Fx})$ at distance $\times$ micrometre on the tail versus fluorescence at the centre of the head (Fo). Based on their observation, they concluded that $50 \mu \mathrm{m}$ gives the best resolution of the method used. Based on our current understanding however, as mentioned later, this measurement is not considered to be robust.

Singh et al. (1988) developed the alkaline version of the Comet Assay in which they used the length of DNA migration (tail length) to quantify the extent of damage. Subsequently, several research groups published papers in which various Comet Assay parameters were used (Table 1). However, with time, most of them were not of frequent or wide use. Of notable importance is the publication by Olive et al. (1990), who used the concept of the tail moment to describe DNA migration. The tail moment calculated by Olive et al. (1990) came to be known as the Olive tail moment (OTM). This parameter is considered to be particularly useful in describing heterogeneity within a cell population, as OTM can pick up variations in DNA distribution within the tail.

Although image analysis on comets has been preferable for continuity in assessing DNA damage by this method, some groups have been working on simple, less time consuming visual scoring methods that do not require special image analysis software. Collins et al. (1995) published a visual scoring method that classifies comets from grades $0-4$ (Fig. 2). In this approach, for example, if 100 comets are scored and each comet assigned a value of 0 to 4 according to its class, the total score for the sample gel will be between 0 and 400 "arbitrary units." Visual scoring is rapid as well as simple and should appeal to those exploring the usefulness of the technique without the need to invest in expensive analytical equipment or software packages (Collins 2004).

Another important publication on visual scoring was by Kobayashi et al. (1995). The scoring system used by them grouped comets into five stages (Fig. 3), but they did not calculate the total score for each gel. Furthermore, Kobayashi et al. (1995) and Collins et al. (1997a) showed that the results of visual scoring correlated very well with image analysis measurements. It is interesting to note that visual scoring based on Collins et al. (1995) is becoming popular especially in biomonitoring and DNA repair studies. About 70 biomonitoring studies have reported DNA damage using visual scoring criteria (Moller 2006). Moreover, visual scoring has the potential to be used for inter-laboratory comparisons.

\section{Significance of staining procedures in comet measurements}

Whether the comets are scored by image analysis or visual scoring, good staining of comets is of paramount importance. Various fluorochromes, which were traditionally used to stain DNA, chromosomes or nuclei, are being used to stain the comets (i.e. 'head' and 'tail'). Ethidium bromide (EB) is most commonly used to stain the DNA on Comet Assay slides (Singh
Fig. 2 Visual classification suggested by Collins et al. (1995). Images of comets (from lymphocytes), stained with DAPI. They represent classes $0-4$ as used for visual scoring
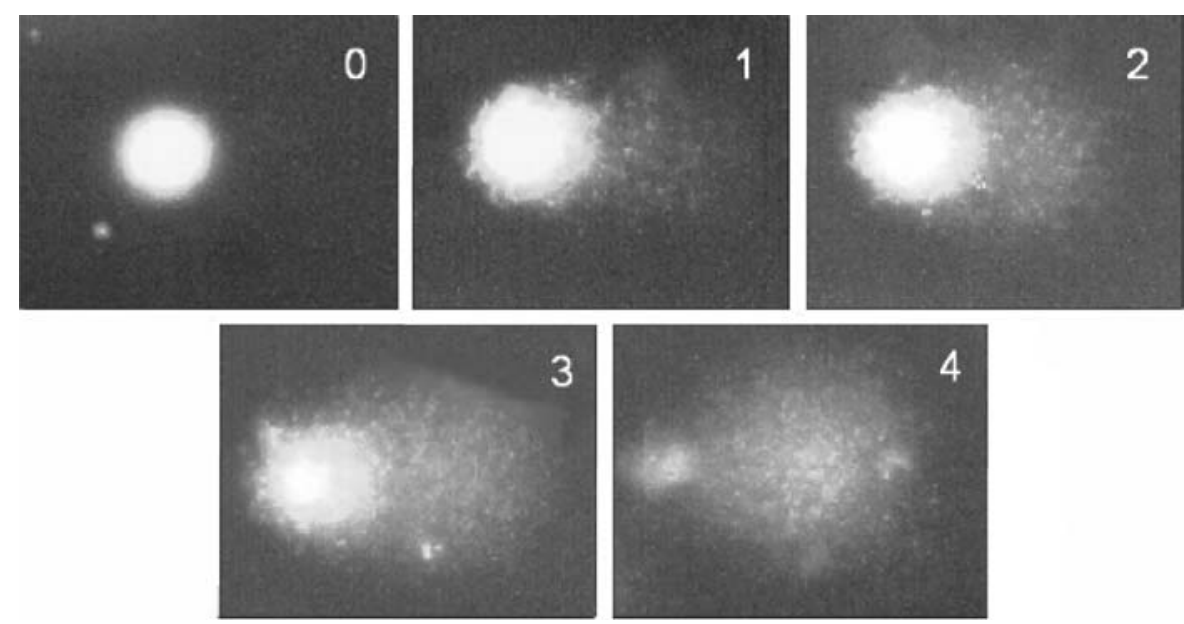


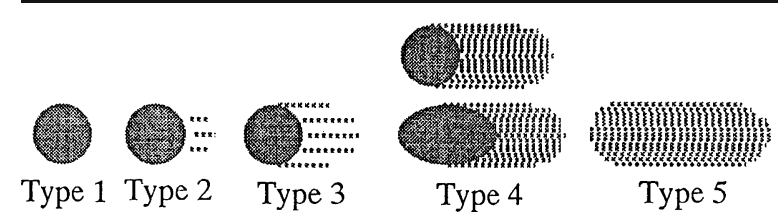

Fig. 3 Schematic of visual classification of comets by Kobayashi et al. (1995). They represent comets of Types 1 to 5

et al. 1988), followed by 4, 6-diamidino-2-phenylindole (DAPI, Gedik et al. 1992). EB is an intercalating dye that binds more efficiently to double-stranded DNA than to single-stranded DNA. DAPI binds predominantly to the major groove of the DNA. The amount of dye binding to the DNA is proportional to the amount of DNA present and, hence, the amount of light emitted after excitation with ultraviolet light of appropriate wavelength. It is important that we use very low concentrations of the dye, as higher concentrations will saturate the system. If the light emitted by the comets is very intense, the image analysis software cannot accurately define certain Comet Assay measurements like OTM, because the centre of gravity (CG) of DNA distribution is not defined correctly (Fig. 4). Other dyes used are SYBR ${ }^{\circledR}$ green/gold (Tice et al. 1998), AO, YOYO dye (Singh et al. 1994) and propidium iodide. In addition, non-fluorescent staining, such as silver stain, has also been used by some workers (Kizilian et al. 1999; Garcia et al. 2007).

For general genotoxicity testing purpose, EB is an excellent choice of Comet Assay stain. EB produces a bright fluorescence, which does not fade easily. Unlike the $\mathrm{SYBR}^{\circledR}$ green stain, EB does not fade during the process of image capturing. This gives the option to work in dim light rather than in completely dark rooms. Furthermore, EB at concentrations in the range of

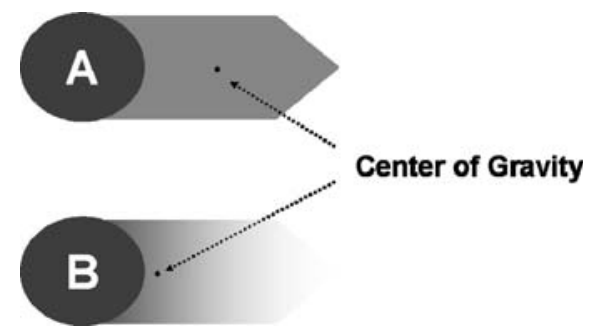

Fig. 4 Schematic diagram explaining how concentration of DNA binding fluorescent dye may affect Comet Assay measurements using image analysis. $A$ A high concentration of DNA binding dye is used, and the tail fluorescence is fully saturated. $B$ Optimal concentration of DNA binding dye is used and the center of gravity of DNA distribution is properly defined
2-20 $\mu \mathrm{g} \mathrm{ml}^{-1}$ gives good quality staining of DNA with a low background signal. We would therefore recommend EB as the first choice of stain for high throughput genetic toxicological studies. YOYO dye
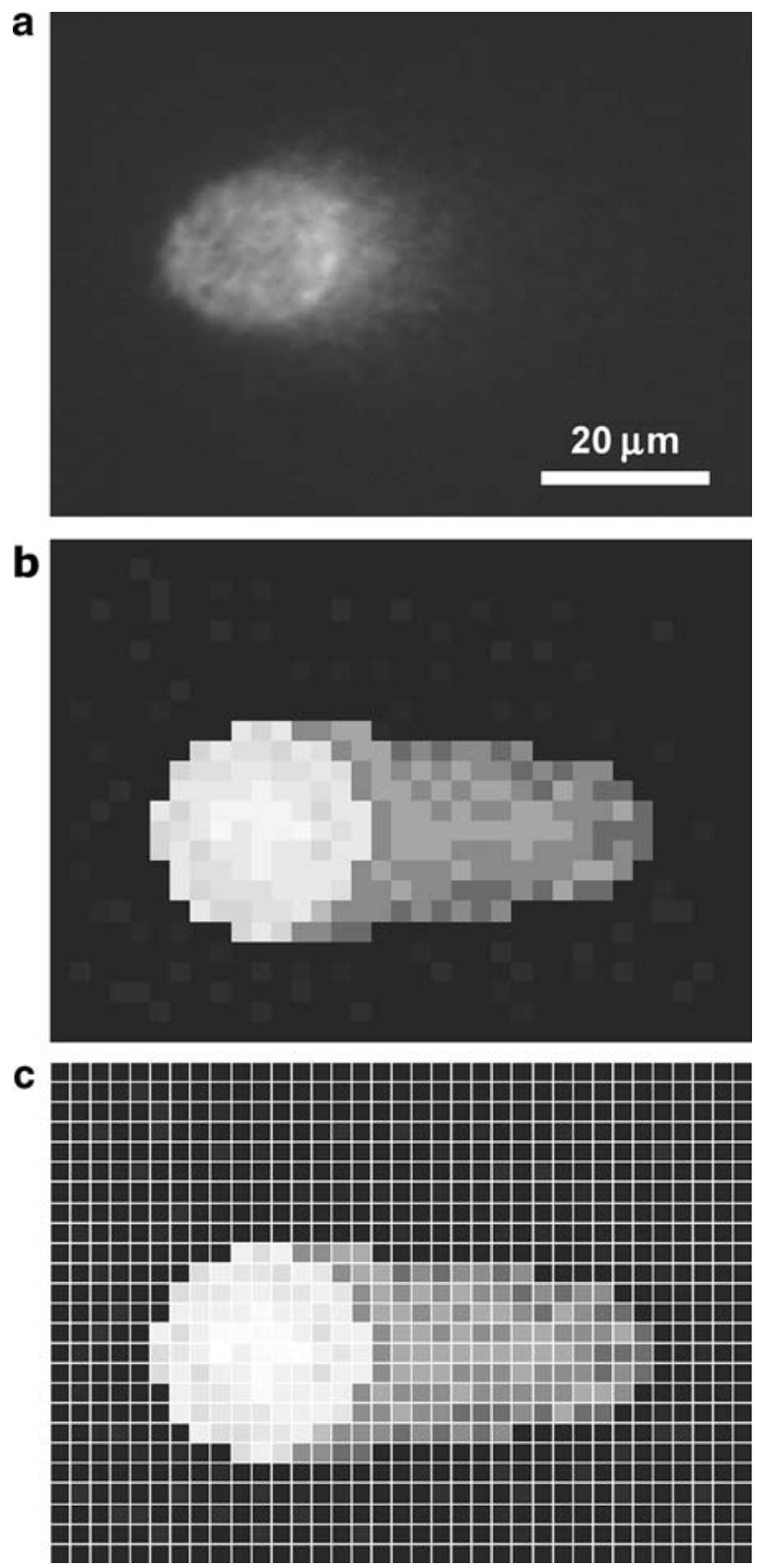

Fig. 5 The model image of a comet. The light emitted from a comet on the slide is detected as an image. The image of a real comet on the microscope slide is shown in (a). A simplified model image of comet (b) can be used to demonstrate the measurement of Comet Assay parameters. An image is composed of separate pixels (c). The size of this model image of a comet is $35 \times 25$ pixels. The images that cameras record, have many pixels (e.g. $750 \times 550,1,300 \times 1,030$ ), so individual pixels cannot be discerned in (a) unless the image is considerably enlarged 


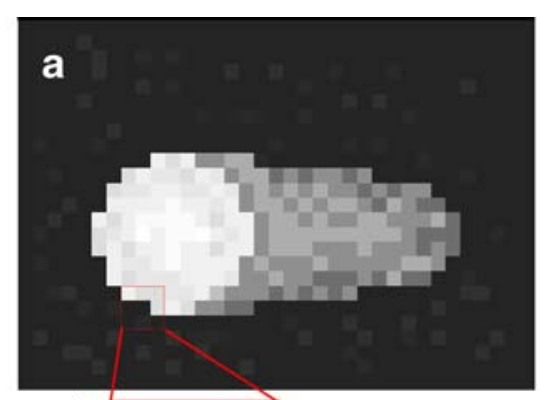

b


Fig. 6 Conversion of light intensity to grey values on an image. Information on an image is coded as grey values. An image of a comet is composed of separate pixels (a), where each pixel has a grey value, as shown in (b) for a small image area outlined in red in (a). The model image is an 8-bit image with available grey values $0-255$. The relationship between the grey value of a pixel on the image and light intensity (fluorescence) that a camera element detects is linear (c)

gives a strong fluorescence signal and is particularly useful when cells with low DNA content are used in the Comet Assay. However, YOYO dye is expensive and cannot be stored for longer periods of time. $\mathrm{SYBR}^{\circledR}$ green/gold also gives a bright fluorescence, but fading during the process of scoring is definitely a problem. SYBR ${ }^{\circledR}$ gold stains both double-stranded and single-stranded DNA and is considered better than $\mathrm{SYBR}^{\circledR}$ green. Although silver staining is considered to be cheaper in the sense that it does not require use of a fluorescence microscope, it appears to be more time consuming and have a lower resolution compared to fluorescence staining. It also requires proper optimisation, as it may incur a lot of background staining.

\section{Principles of image analysis in Comet Assay}

It is difficult to ascertain who used commercially available software for the first time. Presently, different software packages are used for measurement of comet parameters on the basis of image analysis. Although these software packages may differ slightly the way they calculate DNA damage, the underlying principles of image analysis are the same (Vilhar 2004; http://www.botanika.biologija.org/exp/comet/ Comet-principles).

The first step is to visualise the comets under the fluorescence microscope fitted with appropriate filters
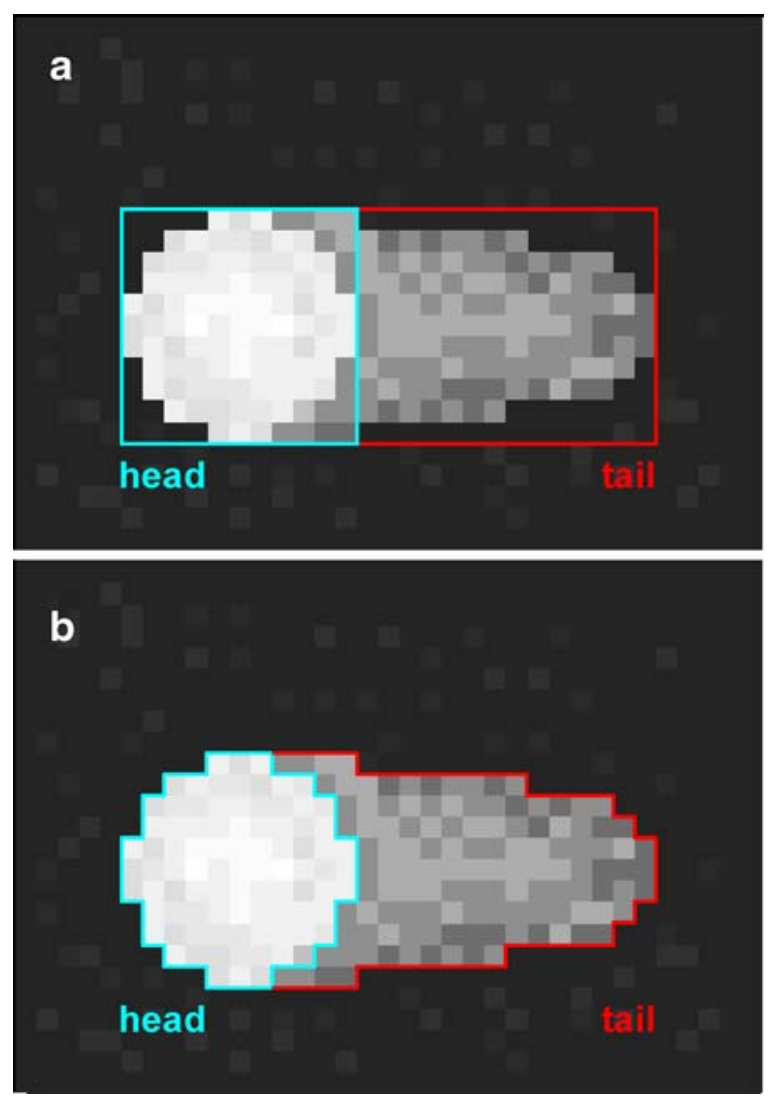

Fig. 7 Segmentation of the comet image. During the segmentation step, the regions of interest (ROI) for measurement of comet head and tail are defined. In some software packages, the user can interactively draw rectangles that define the head and the tail ROI (a; box segmentation). In others, the head and the tail are detected automatically and outlined (b; close fitting segmentation) 
(depending on the fluorochrome used) and capture the image using a camera. The camera records the intensity of light emitted from each point on the comet and converts it into electrical signals. These electrical signals are then sent to the computer along with their coordinates, and the computer decodes these signals and displays the image on the screen (Fig. 5). An image is composed of small dots called pixels. Each pixel represents one light sensitive element of the camera, and the numbers corresponding to light intensity detected for each pixel (grey values) are stored in a computer file (Fig. 6). Once the image is converted into numbers as shown in Fig. 6, the actual image analysis is initiated. The next step is to define the head and the tail of the comet. Different software packages use different approaches to detect the head and the tail (Fig. 7). Once the 'head' and 'tail' region are defined, the tail length is measured in terms of pixels, which are then converted into microns. The light intensities originating from the head and tail
Fig. 8 Grey values for the head, the tail and the background regions of the model comet image. Box segmentation is shown, with head indicated in blue, the tail in orange and the background in yellow. The pixel column eight is in blue font in the table. The pixel column number is indicated in italics

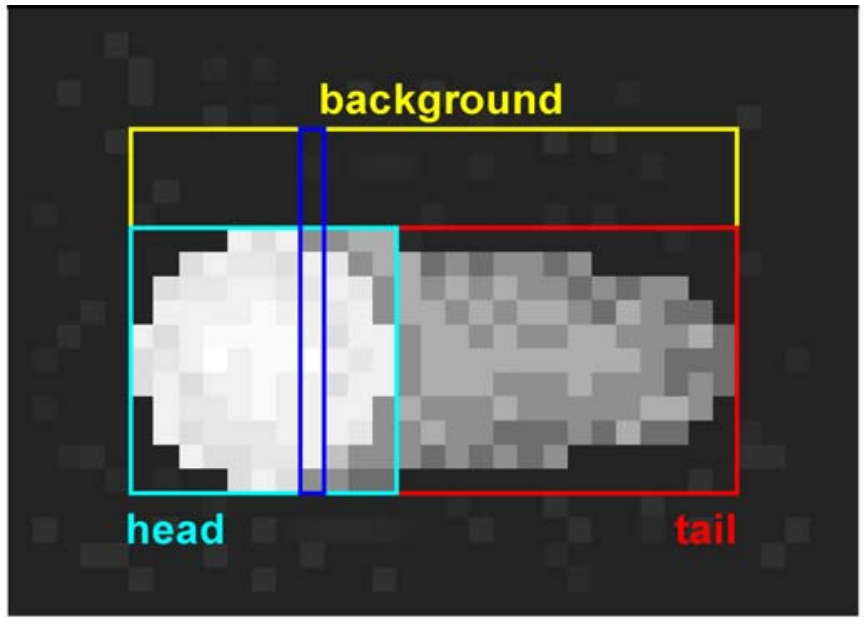

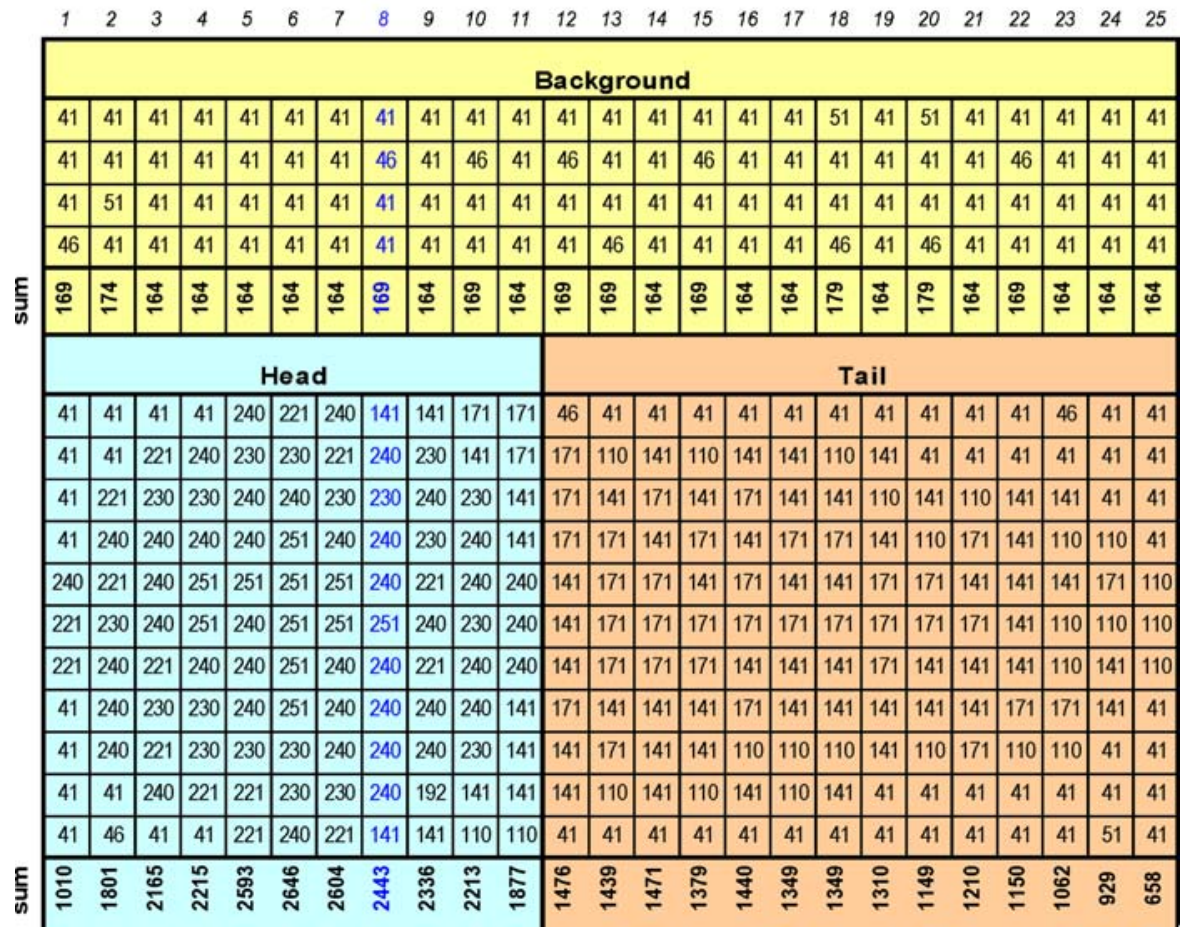


parts of the comet are used to calculate different comet parameters (Fig. 8). The background fluorescence is subtracted from head and tail intensities to get the true fluorescence as described in Table 2.

\section{Standardisation of Comet Assay measurements}

The Comet Assay has mainly remained an assay of academic and scientific interest until quite recently. Currently, the Comet Assay has however the potential to be used as a tool in genotoxicity testing and regulatory submissions for new chemicals and mixtures (Tice et al. 2000; Hartmann et al. 2003; Kumaravel and Jha 2006). In an attempt to make the assay more sensitive and reliable, several research groups have come out with unique procedures and specialised measures of DNA migration. Attempts have been made to make this assay widely acceptable, by correlating the results with other well-established assays (e.g. micronucleus assay) whilst determining the genotoxicity (Raisuddin and Jha 2004). Before it can be accepted as a regulatory tool, this assay has to be harmonised in terms of its methodology and interpretations and should be demonstrated to be reliable, accurate and transferable between laboratories. An expert panel at an International Workshop on Genotoxicity Test Procedures (IWGTP) held in Washington, DC, in 1999, identified minimal experimental and methodological standards necessary to ensure that the results of the Comet Assay studies would be acceptable as being informative by knowledgeable scientists and regulatory authorities in this

Table 2 Subtraction of the background signal for each pixel column of the comet on the model comet image

\begin{tabular}{|c|c|c|c|c|c|c|c|}
\hline ROI & $\begin{array}{l}\text { Number } \\
\text { of pixel } \\
\text { column }\end{array}$ & $\begin{array}{l}\text { Recorded comet } \\
\text { intensity } \\
\text { (sum of } 11 \text { pixels) }\end{array}$ & $\begin{array}{l}\text { Recorded } \\
\text { background } \\
\text { intensity } \\
\text { (sum of } 4 \text { pixels) }\end{array}$ & $\begin{array}{l}\text { Average } \\
\text { background } \\
\text { intensity } \\
\text { (per pixel) }\end{array}$ & $\begin{array}{l}\text { Scaled } \\
\text { background } \\
\text { intensity } \\
\text { (for } 11 \text { pixels) }\end{array}$ & $\begin{array}{l}\text { Background-corrected } \\
\text { comet intensity } \\
\text { (sum of } 11 \text { pixels) }\end{array}$ & $\begin{array}{l}\text { Cumulative } \\
\text { comet } \\
\text { intensity }\end{array}$ \\
\hline \multirow[t]{11}{*}{ Head } & 1 & 1,010 & 169 & 42 & 465 & 545 & 545 \\
\hline & 2 & 1,801 & 174 & 44 & 479 & 1,323 & 1,868 \\
\hline & 3 & 2,165 & 164 & 41 & 451 & 1,714 & 3,582 \\
\hline & 4 & 2,215 & 164 & 41 & 451 & 1,764 & 5,346 \\
\hline & 5 & 2,593 & 164 & 41 & 451 & 2,142 & 7,488 \\
\hline & 6 & 2,646 & 164 & 41 & 451 & 2,195 & 9,683 \\
\hline & 7 & 2,604 & 164 & 41 & 451 & 2,153 & 11,836 \\
\hline & 8 & 2,443 & 169 & 42 & 465 & 1,978 & 13,814 \\
\hline & 9 & 2,336 & 164 & 41 & 451 & 1,885 & 15,699 \\
\hline & 10 & 2,213 & 169 & 42 & 465 & 1,748 & 17,447 \\
\hline & 11 & 1,877 & 164 & 41 & 451 & 1,426 & 18,873 \\
\hline \multirow[t]{14}{*}{ Tail } & 12 & 1,476 & 169 & 42 & 465 & 1,011 & 1,011 \\
\hline & 13 & 1,439 & 169 & 42 & 465 & 974 & 1,986 \\
\hline & 14 & 1,471 & 164 & 41 & 451 & 1,020 & 3,006 \\
\hline & 15 & 1,379 & 169 & 42 & 465 & 914 & 3,920 \\
\hline & 16 & 1,440 & 164 & 41 & 451 & 989 & 4,909 \\
\hline & 17 & 1,349 & 164 & 41 & 451 & 898 & 5,807 \\
\hline & 18 & 1,349 & 179 & 45 & 492 & 857 & 6,664 \\
\hline & 19 & 1,310 & 164 & 41 & 451 & 859 & 7,523 \\
\hline & 20 & 1,149 & 179 & 45 & 492 & 657 & 8,179 \\
\hline & 21 & 1,210 & 164 & 41 & 451 & 759 & 8,938 \\
\hline & 22 & 1,150 & 169 & 42 & 465 & 685 & 9,624 \\
\hline & 23 & 1,062 & 164 & 41 & 451 & 611 & 10,235 \\
\hline & 24 & 929 & 164 & 41 & 451 & 478 & 10,713 \\
\hline & 25 & 658 & 164 & 41 & 451 & 207 & 10,920 \\
\hline
\end{tabular}

The data for the boxed segmentation of the model image are shown in Fig. 8 . The data for pixel column eight in Fig. 8 are shown in blue. In this example, a narrow rectangle of 4-pixel height is used as a background (see Fig. 8). The percentage of DNA in the tail is 10,920/ $29,793=0.37=37 \%$. The background corrected comet, head or tail intensities are used in all further calculations of the comet parameters 
field (Tice et al. 2000; Hartmann et al. 2003). The expert panel recognised that different methods have been used to analyse 'comets' in the assay. At the IWGTP, however, the expert panel did not recommend any particular measurement of comet migration to be more useful than any other measure. However, the expert panel did recommend that, when using derived measurements (e.g. tail moment), data on primary measurements (e.g. tail length and \% Tail DNA) should also be presented in the analyses (Tice et al. 2000). Similar recommendations were put forwards by Hartmann et al. (2003). However, for peer-review publications, normally, only one set of measurements (e. g. either tail moment or \% Tail DNA) is presented.

Kumaravel and Jha (2006) defined the most reliable comet measurements that would truly reflect the extent of DNA damage induced by low linear energy transfer ionising radiation. The authors approached this question by performing alkaline Comet Assay on human peripheral blood lymphocytes irradiated with graded doses of ${ }^{137} \mathrm{Cs}$ gamma radiation and correlating the various comet measurements with the radiation dose. As DNA damage produced is directly proportional to the radiation dose, any change in dose should be reflected in proportional change in the comet measurements. They concluded that only a few comet measurements provided by the image analysis software correlated well with gamma radiation dose. Further retrospective analysis from in vitro and in vivo experiments using chemicals also suggested that OTM and \% Tail DNA gave good correlations with the dose of genotoxic agents used and were the most reliable comet measurements. Statistically, the authors did not find much difference between OTM and \% Tail DNA in analysing extent of DNA damage.

Although OTM appeared to be the most statistically significant measurement (Kumaravel and Jha 2006), the inter-laboratory comparison of results seems to be difficult for this parameter. OTM is calculated as a product of two factors: the percentage of DNA in the tail (\%Tail DNA) and the distance between the intensity centroids (centres of gravity) of the head and the tail along the $x$-axis of the comet. Hence, OTM is an absolute parameter with a measurement unit $\mu \mathrm{M}$ (Vilhar 2004; http://www. botanika.biologija.org/exp/comet/Comet-principles). This requires that the image analysis system is geometrically calibrated before comet measurement (i.e. the number of pixels per micrometre is known for different microscope objectives). If the system is not calibrated, inter-laboratory comparisons are difficult. On the other hand, many published reports quote OTM values without a unit (micrometre), which makes inter-laboratory comparisons impossible. In addition, OTM calculation includes the distance between the intensity centroids of the head and the tail, which depends upon conditions of electrophoresis (e.g. electrophoresis time), and algorithms used to define the $\mathrm{CG}$ of DNA distribution vary among different software packages. Under these circumstances, it is advisable to use \% Tail DNA for regulatory purposes and for inter-laboratory comparisons. In addition, for studies involving multiple electrophoresis runs, the \% Tail DNA, rather than OTM, would be a better descriptor of DNA damage for all the reasons given above. Kumaravel and Jha (2006) recommended that, for scientific purposes, both OTM and \% Tail DNA could be used. Based on these findings, the Fourth IWGT also recommended the use of \% Tail DNA for regulatory studies (Burlinson et al. 2007). The Japanese Centre for the Validation of Alternative Methods (JaCVAM) are also recommending \% Tail DNA for their inter-laboratory Comet Assay trials. As JaCVAM initiative aims to facilitate Organization for Economic Cooperation and Development acceptance of Comet Assay as a regulatory tool, this parameter (i.e. \% Tail DNA) would play an important role in harmonisation of the laboratory protocols and inter-laboratory comparison of the data (Burlinson B, communication at the 7th International Comet Assay Workshop, Coleraine, UK, 2007).

\section{Identification and measuring the 'Clouds'}

'Clouds' or 'hedgehogs' are important observations in most Comet Assay experiments. These are cells with extensive DNA migration that are outside the measurement capabilities of the image analysis system or may give inappropriate measurements when image analysis is used. Clouds are therefore scored only by visual analysis. They are characterised by a small or absent head with a highly diffused tail that is physically separate from the head. Accurate identification of clouds comes with practice and experience; hence, it is important that clouds are identified correctly whilst scoring slides using image analysis systems. Ideally, they should be 
scored visually and recorded alongside the results of image analysis.

The exact origin of clouds is not clear, but it is assumed that apoptotic cells lead to clouds. This has been observed in Rat-1 cells exposed to irradiation with 10 Gy gamma rays, where the cells underwent apoptosis $24 \mathrm{~h}$ after irradiation and produced clouds in Comet Assay (Kumaravel TS; unpublished observations). Interestingly, cells treated with hydrogen peroxide for approximately $5 \mathrm{~min}$ and processed immediately (assuming that apoptotic process cannot be initiated and completed in $5 \mathrm{~min}$ ) also gave rise to clouds. Moreover, cells treated with high doses of gamma radiations and processed immediately gave a similar response. Clouds are routinely seen in in vitro and in vivo Comet Assay experiments (particularly where cells are collected by scraping, e.g. stomach). These observations suggest that, in addition to apoptosis, clouds are also induced by high levels of DNA damage as well as in necrotic cells. It is also observed that, sometimes, identical experimental conditions can result either in measurable comets or in clouds. This phenomenon is particularly seen in treatment with hydrogen peroxide and methyl methanesulphonate (Collins 2004; Speit et al. 2004) when used in conjunction with enzymes such as endonucleases. To confirm whether clouds really represent apoptotic cells, more experiments under different exposure conditions are required bearing in mind that apoptosis is an irreversible process. There is insufficient information in literature on this issue, and more studies are required to elucidate this phenomenon.

There are several questions on how to integrate clouds with other Comet Assay measurements. The usual practice is to determine the percentage of clouds on each slide. This data is usually presented along with other Comet Assay measurements and cytotoxicity data where an increase in clouds parallels an increase in DNA migration, but this is not always the case. Good scientific judgement should be used in interpreting these data, and further work is necessary to assess how to integrate clouds with other Comet Assay measurements.

\section{Comet assay combined with FISH}

The Comet Assay has also been combined with FISH technique (Comet-FISH) to investigate the localisa- tion of specific gene domains within an individual cell (e.g. p53, her-2). The position of the fluorescent hybridisation spots in the comet head or tail indicates whether the sequence of interest lies within or in the vicinity of a damaged region of DNA. Although not many studies have been performed using this technique, it has a number of potential uses in DNA repair and genomic instability studies. The measurements that can be collected from Comet-FISH experiments are the position (either in head or tail) and number (number of fluorescence spots) of FISH signals after DNA damage. In the assay, depending on the probe region and probe length, the signals can be split or just migrate to the tail. The location of FISH signals (either split or intact) in either head or tail appears to be the best indicator for DNA damage using CometFISH. The splitting of signals appears to be random events depending on whether the DNA damaging agent targets the vicinity of the gene/locus specific indicator of interest. The p53 gene is a well-studied example where the signals split and migrate to the tail immediately after irradiation (McKenna et al. 2003; Kumaravel and Bristow 2005). When allowed to repair for a period of time, the signals return back to the head. More work is necessary to standardise the measurements for the Comet -FISH technique before it is adopted for routine use.

\section{Use of control cells in Comet Assay measurements}

In a typical Comet Assay, electrophoresis methods and differences in cell preparations create a significant source of variation for the measurements. Such variation sometimes makes it difficult to compare results between laboratories, and even within the same laboratory. To overcome this problem, use of slides prepared from cells containing a known amount of DNA damage (also called control cells) are included in every electrophoresis run. Control cells consistently produce comets with predetermined DNA migration in the tails. Some researchers define acceptance criteria for experiments based on DNA migration observed in control cells. If the DNA migration in control cells does not fall within the laboratory's historical control values, the data generated from that electrophoresis run are rejected. Some researchers use the data for DNA migration in control cells to normalise with those from other samples. Control cells are produced from stable 
cells that have been irradiated with known amount of gamma radiation, aliquoting them in small cryovials followed by immediate flash freezing. There are some commercial sources of control cells such as Trevigen ${ }^{\circledR}$, who prepare their control cells by treating them with known concentrations of etoposide. There was no recommendation for use of control cells in any of the IWGT workshops. We will recommend the use of control cells in each and every electrophoresis run as a best practice to generate high quality Comet Assay data.

\section{Conclusions}

In conclusion, 'measurements' form an important part of Comet Assay analysis. Robust Comet Assay data and interpretation depend on good and optimum slide staining, adoption of robust image analysis practices and use of reliable and meaningful Comet Assay measurement (e.g. \% Tail DNA or OTM). As OTM values can differ widely between laboratories and/or with different software packages, \% Tail DNA is considered appropriate for regulatory or inter-laboratory comparison studies. Moreover, for all studies that involve multiple electrophoresis runs, it is recommended that \% Tail DNA be used to reduce variability in the results. It is generally accepted that visual scoring is as comparable as image analysis; however, image analysis can provide additional information (e.g. determination of the cell cycle status of cells by measuring their DNA content) that may be important in the characterisation of the genotoxicity of some compounds. It should be noted that clouds form an important form of Comet Assay measurement, especially when the DNA damage is extensive. It is therefore important that clouds are actively and accurately looked for, recorded and appropriately interpreted in Comet Assay experiments. These practices will help to establish Comet Assay as a reliable and robust tool for fundamental biological research, in addition to hazard and risk assessment, the main aims of the field of genetic toxicology.

Acknowledgement/Disclaimer BV's contribution to this article was supported by a grant from the Ministry of Higher Education, Science and Technology of Slovenia (BV: grant no. P1-0212). ANJ has not received any financial support from Advanced Technologies (Cambridge) Ltd.

\section{References}

Bichler J, Cavin C, Simic T, Chakraborty A, Ferk F, Hoelzl C, et al. Coffee consumption protects human lymphocytes against oxidative and 3-amino-1-methyl-5H-pyrido[4,3-b] indole acetate (Trp-P-2) induced DNA-damage: results of an experimental study with human volunteers. Food Chem Toxicol 2007. Epub ahead of print.

Burlinson B, Tice RR, Speit G, Agurell E, Brendler-Schwaab SY, Collins AR, et al. In vivo Comet Assay workgroup, part of the Fourth International Workgroup on Genotoxicity Testing: results of the in vivo Comet Assay workgroup. Mutat Res 2007;627:31-5.

Collins AR. Comet Assay for DNA damage and repair: principles, applications and limitations. Mol Biotechnol 2004;26:249-61.

Collins AR, Duthie SJ, Dobson VL. Direct enzymic detection of endogenous oxidative base damage in human lymphocyte DNA. Carcinogenesis 1993;14:1733-35.

Collins AR, Ma AG, Duthie SJ. The kinetics of repair of oxidative DNA damage (strand breaks and oxidised pyrimidine) in human cells. Mutat Res 1995;336:69-77.

Collins A, Dusinska M, Franklin M, Somorovska M, Petrovska $\mathrm{H}$, Duthie S, et al. Comet Assay in human biomonitoring studies: reliability, validation, and applications. Environ Mol Mutagen 1997a;30:139-46.

Collins AR, Mitchell DL, Zunino A, de Wit J, Busch D. UVsensitive rodent mutant celllines of complementation groups 6 and 8 differ phenotypically from their human counterparts. Environ Mol Mutagen 1997b;29:152-60.

Collins AR, Dusinská M, Horská A. Detection of alkylation damage in human lymphocyte DNA with the comet assay. Acta Biochim Pol 2001a;48:611-4.

Collins BH, Horská A, Hotten PM, Riddoch C, Collins AR. Kiwifruit protects against oxidative DNA damage in human cells and in vitro. Nutr Cancer 2001b;39:148-53.

Collins AR. Comet assay for DNA damage and repair: principles, applications and limitations. Mol Biotechnol 2004;26:249-261.

Comet Assay interest group website. http://cometassay.com/ (accessed 06, 2007).

Dixon DR, Pruski AM, Dixon LRJ, Jha AN. Marine invertebrate eco-genotoxicology: a methodological overview. Mutagenesis 2002;17:495-507.

Fairbairn DW, Olive PL, O'Neill KL. The Comet Assay: A comprehensive review. Mutat Res 1995;339:37-59.

Fisher AE, Burke D, Routledge MN. Can irradiation of rectal tumour cells from patient biopsy predict outcome of radiotherapy? Proceedings of the Genome Stability network/United Kingdom Environmental Mutagen Society Joint Congress, University of Cardiff, 1-4 July 2007.

Garcia O, Romero I, González JE, Mandina T. Measurements of DNA damage on silver stained comets using free Internet software. Mutat Res 2007;627:186-90.

Gichner T, Patkova Z, Szakova J, Demnerova K. Cadmium induces DNA damage in tobacco roots, but no DNA damage, somatic mutations or homologous recombination in tobacco leaves. Mutat Res 2004;559:49-57.

Gichner T, Mukherjee A, Veleminsky J. DNA staining with the fluorochromes EtBr, DAPI and YOYO-1 in the comet 
assay with tobacco plants after treatment with ethyl methanesulphonate, hyperthermia and DNase-I. Mutat Res 2006;605:17-21.

Gedik CM, Ewen SWB, Collins AR. Single-cell gel electrophoresis applied to the analysis of UV-C damage and its repair in human cells. Int J Radiat Biol 1992;62:313-20.

Hartmann A, Agurell E, Beevers C, Brendler-Schwaab S, Burlinson B, Clay P, et al. 4th International Comet Assay Workshop. Recommendations for conducting the in vivo alkaline Comet Assay. Mutagenesis 2003;18:45-51.

Jha AN. Genotoxicological studies in aquatic organisms: An overview. Mutat Res 2004;552:1-17.

Kizilian N, Wilkins RC, Reinhardt P, Ferrarotto C, McLean JRN, Mc-Namee JP. Silver-stained comet assay for detection of apoptosis. Biotechniques 1999;27:926-30.

Kobayashi H, Sugiyama C, Morikawa Y, Hayashi M, Sufuni T. Comparison between manual microscopic analysis and computerised image analysis in single cell gel electrophoresis assay. MMS Commun 1995;3:103-15.

Kruman II, Kumaravel TS, Lohani A, Pedersen WA, Cutler RG, Kruman Y, et al. Folic acid deficiency and homocysteine impair DNA repair in hippocampal neurons and sensitize them to amyloid toxicity in experimental models of Alzheimer's disease. J Neurosci 2002;22: 1752-62.

Kumaravel TS, Bristow RG. Detection of genetic instability at HER-2/neu and p53 loci in breast cancer cells using Comet-FISH. Breast Cancer Res Treat 2005;91:89-93.

Kumaravel TS, Jha AN. Reliable Comet Assay measurements for detecting DNA damage induced by ionising radiation and chemicals. Mutat Res 2006;605:7-16.

Lee RF, Steinert S. Use of the single cell gel electrophoresis/ Comet Assay for detecting DNA damage in aquatic (marine and freshwater) animals. Mutat Res 2003;544: 43-64.

McKenna DJ, Rajab NF, McKeown SR, McKerr G, McKelveyMartin VJ. Use of the comet-FISH assay to demonstrate repair of the TP53 gene region in two human bladder carcinoma cell lines. Radiat Res 2003;159:49-56.

Miyamae Y, Iwasaki K, Kinae N, Tsuda S, Murakami M, Tanaka $\mathrm{M}$, et al. Detection of DNA lesions induced by chemical mutagens using the single-cell gel electrophoresis (Comet) assay. 2. Relationship between DNA migration and alkaline condition. Mutat Res 1997;393: 107-13.
Moller P. Assessment of reference values for DNA damage detected by the comet assay in human blood cell DNA. Mutat Res 2006;612:84-104.

Olive PL, Banath JP, Durand RE. Heterogeneity in radiationinduced DNA damage and repair in tumor and normal cells measured using the "Comet" assay. Radiat Res 1990;122:86-94.

Ostling O, Johanson KJ. Microelectrophoretic study of radiationinduced DNA damages in individual mammalian cells. Biochem Biophys Res Commun 1984;123:291-8.

Raisuddin S, Jha AN. Relative sensitivity of fish and mammalian cells to sodium arsenate and arsenite as determined by alkaline single cell gel electrophoresis and cytokinesisblock micronucleus assay. Environ Mol Mutagen 2004; 44:83-9.

Santos SJ, Singh NP, Natarajan AT. Fluorescence in situ hybridization with comets. Exp Cell Res 1997;232:407-11.

Singh NP, McCoy MT, Tice RR, Schneider EL. A simple technique for the quantitation of low levels of DNA damage in individual cells. Exp Cell Res 1988;175:184-91.

Singh NP, Stephens RE, Schneider EL. Modifications of alkaline microgel electrophoresis for sensitive detection of DNA damage. Int J Radiat Biol 1994;66:23-28.

Smith AJO, Almeida GM, Thomas AL, Jones GD. Comet assay measures of irinotecan-induced DNA damage in vitro and in vivo. Proceedings of the Genome Stability network/ United Kingdom Environmental Mutagen Society Joint Congress University of Cardiff, 1-4 July 2007.

Speit G, Schütz P, Bonzheim I, Trenz K, Hoffmann H. Sensitivity of the FPG protein towards alkylation damage in the comet assay. Toxicol Lett 2004;146:151-8.

Tice RR, Furedi-Machacek M, Satterfield D, Udumudi A, Vasquez M, Dunnick JK. Measurement of micronucleated erythrocytesand DNA damage during chronic ingestion of phenolphthalein intransgenic female mice heterozygous for the p53 gene. Environ Mol Mutagen 1998;31:113-24.

Tice RR, Agurell E, Anderson D, Burlinson B, Hartmann A, Kobayashi H, et al. Single cell gel/Comet Assay: guidelines for in vitro and in vivo genetic toxicology testing. Environ Mol Mutagen 2000;35:206-21.

Vilhar B. Help! There is a comet in my computer! A dummy's guide to image analysis used in the comet assay. University of Ljubljana, http://www.botanika.biologija.org/exp/comet/ Comet-principles.pdf (accessed 07, 2007); 2004. 